\title{
The occupational contribution to severe exacerbation of asthma
}

\author{
P.K. Henneberger, M.C. Mirabelli, M. Kogevinas, J.M. Antó, E. Plana, \\ A. Dahlman-Höglund, D.L. Jarvis, H. Kromhout, L. Lillienberg, D. Norbäck, \\ M. Olivieri, K. Radon, K. Torén, I. Urrutia, S. Villani and J.P. Zock
}

ABSTRACT: The goal of this study was to identify occupational risk factors for severe exacerbation of asthma and estimate the extent to which occupation contributes to these events.

The 966 participants were working adults with current asthma who participated in the follow-up phase of the European Community Respiratory Health Survey. Severe exacerbation of asthma was defined as self-reported unplanned care for asthma in the past 12 months. Occupations held in the same period were combined with a general population job-exposure matrix to assess occupational exposures.

74 participants reported having had at least one severe exacerbation event, for a 1-yr cumulative incidence of $\mathbf{7 . 7 \%}$. From regression models that controlled for confounders, the relative risk (RR) was statistically significant for low (RR 1.7, 95\% Cl 1.1-2.6) and high (RR 3.6, 95\% Cl 2.2-5.8) biological dust exposure, high mineral dust exposure (RR 1.8, 95\% Cl 1.02-3.2), and high gas and fumes exposure (RR 2.5, 95\% $\mathrm{Cl}$ 1.2-5.5). The summary category of high dust, gas, or fumes exposure had RR 3.1 (95\% Cl 1.9-5.1). Based on this RR, the population attributable risk was $14.7 \%$ among workers with current asthma.

These results suggest occupation contributes to approximately one in seven cases of severe exacerbation of asthma in a working population, and various agents play a role.

KEYWORDS: Asthma, exacerbation, occupational, work-related

A sthma is common among adults in Europe, with a prevalence of $\sim 7 \%$ [1]. Conditions at work are one of the causes of asthma exacerbations, as are environmental exposures in other settings (e.g. home and ambient environment), failures in medication regimens and viral infections. Work-related asthma includes both occupational asthma (OA) caused by work, and work-exacerbated asthma (WEA), in which existing asthma is made worse by work. A 2003 statement of the American Thoracic Society concluded that $15 \%$ of new-onset asthma among adults was due to occupation, but that there could be much more sickness and loss of productivity due to work-related exacerbation of existing asthma [2]. Six recent epidemiological studies conducted in five countries estimated the frequency of WEA, separate from cases of OA caused by work [3-8]. From these studies, the prevalence of WEA expressed as a percentage of working adults with asthma ranged from $14 \%$ to $24 \%$, with a median of $19 \%[3,5,6,8]$. A variety of agents have been associated with WEA, such as irritant gases and fumes [9-11], accidental spills [11], and second-hand cigarette smoke [9, 11-13]. Other implicated exposures include common aeroallergens, emotional stress, physical exercise and extremes in temperature $[5,8,9,11,14,15]$. WEA has generally received less attention than $\mathrm{OA}$, and a better understanding of the causes of WEA is needed to plan preventive interventions.

Data from the first European Community Respiratory Health Survey (ECRHS I) have already been used to investigate the frequency of prevalent work-related asthma [16]. This prior investigation did not consider asthma onset separately from exacerbation of existing asthma when determining the impact of occupation. More recently, investigators used data from the follow-up phase of the ECRHS (ECRHS II) to examine the association of asthma onset with occupational exposures [17]. ECRHS II data also provided a unique opportunity to study the relationship of exacerbation of asthma to occupational exposures.

The goals of the current study were to identify occupational risk factors for severe exacerbation of asthma and to estimate the extent that occupation contributes to these events. Past
AFFILIATIONS

For author affiliation details, please refer to the Acknowledgements section.

CORRESPONDENCE

P.K. Henneberger

National Institute for Occupational Safety and Health

Centers for Disease Control and Prevention MS H2800 1095 Willowdale Road Morgantown WV 26505 USA E-mail:pkh0@cdc.gov

Received: Aug 252009

Accepted after revision: Feb 212010 First published online: March 292010 
studies have started with asthma cases, evaluated these cases individually to determine WEA status, and then expressed the frequency of WEA as a percentage of asthma cases [3-8]. Unlike previous studies, the current investigation used a riskset approach in which ECRHS II participants with severe exacerbation of asthma were identified, and this outcome was modelled with covariates for occupational exposure to derive estimates of relative and attributable risk.

\section{METHODS}

\section{Study participants}

Individuals included in the current investigation had taken part in both the first and second rounds of ECRHS [18]. In ECRHS I, male and female adults aged 20-44 yrs were randomly selected from the local population to complete a short screening questionnaire (stage 1). A subset of stage 1 respondents were selected either at random ("random sample") or because they had reported respiratory symptoms ("symptomatic sample") to take part in stage 2 clinical evaluations. The random sample included some people with breathing problems, but the symptomatic sample comprised only participants who had reported recently waking with shortness of breath, having an asthma attack or taking asthma medications. Those invited for ECRHS II were those who had completed stage 1 of the ECRHS I, had been selected for stage 2 , and had provided at least their smoking status in ECRHS I.

Individuals potentially eligible for inclusion in this investigation were the 9,812 ECRHS II participants from both random and symptomatic samples in 26 study centres from 11 European nations and the USA who took part in the period 1998-2003. These participants represent $59 \%$ of the 16,692 ECRHS I participants from the same countries that were eligible for ECRHS II. The participants for the current investigation were ECRHS II participants with current asthma who had worked in the 12 months before being surveyed. The selection criteria are outlined in table 1.

Starting with 9,812 ECRHS II adult participants, there were 966 who fulfilled the selection criteria for this investigation, as summarised in figure 1.

\section{Main outcome: severe exacerbation of asthma}

Using responses to items on the ECRHS II questionnaire, a severe exacerbation of asthma was defined as a report of any one of the following four types of unplanned care for asthma in the past 12 months: 1) treatment for breathing problems in a

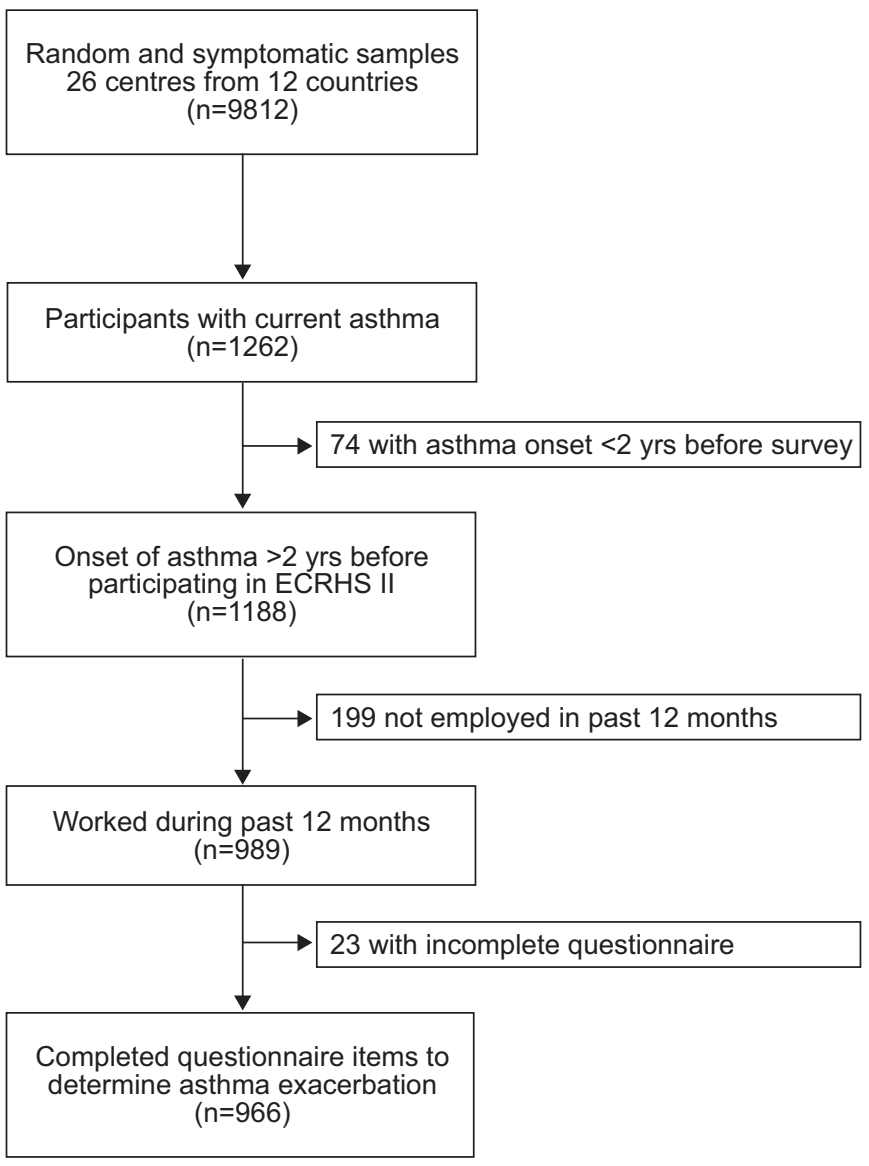

FIGURE 1. Identification of working adults with current asthma among European Community Respiratory Health Survey follow-up (ECRHS II) participants.

\section{TABLE 1 Selection criteria}

Fulfilled the definition of current asthma, similar to that used in a recent publication [19]

Reported ever having asthma confirmed by a doctor [20]

And one or more of the following:

At least one attack of asthma in the past 12 months

Currently taking medicines for asthma

At least one of the following respiratory symptoms in the past 12 months:

Wheezing

Nocturnal tightness in the chest

Attack of shortness of breath when at rest during the day

Attack of shortness of breath following strenuous activity

Being awoken by an attack of shortness of breath

Onset of asthma $>2$ yrs before participating in the ECRHS II survey (i.e. current age minus age at onset $>2$ yrs); this criterion was intended to clarify

it was exacerbation of asthma, and not onset of asthma, that was being studied

Worked during the past 12 months

Completed questionnaire items used to define exacerbation of asthma 
hospital casualty department or emergency room; 2) hospitalisation overnight because of breathing problems; 3) treatment for breathing problems at home in an emergency by a general practitioner; 4) use of oral steroids when needed to control symptoms.

These criteria are consistent with the definition of severe exacerbation of asthma as proposed by the European Agency for the Evaluation of Medicinal Products [21].

\section{Self-reported work-related exacerbation of asthma symptoms}

An item on the questionnaire allowed respondents to indicate which jobs ever made their chest tight or wheezy. We determined who reported this problem with jobs held in the past 12 months to create a variable for self-reported workrelated exacerbation of asthma symptoms. Such reports have been used in studies of WEA [7,8]. While this type of question is susceptible to reporting bias, the raw results are presented to allow comparison with findings from other studies.

\section{Occupation and occupational exposures}

Each ECRHS II participant completed a work history, and occupations from the past 12 months were coded using the ISCO-88 coding system [22]. If a subject had more than one job in the past 12 months, all were coded and associated with that individual. The job codes were then used in two ways to characterise exposure.

First, occupations were grouped into wider categories. A low exposed reference group was defined a priori to include individuals who only worked in professional, clerical and administrative jobs (white collar jobs). This is the same comparison group that was used in a recent study of newonset asthma and occupation in the ECRHS II [17].

Secondly, work-related exposures were assessed for each participant by linking their occupational codes to a general population job-exposure matrix (JEM). The JEM had been developed by two experienced industrial hygienists who assigned a semi-quantitative exposure level (i.e. no, low and high) to job titles for each of three types of work-related exposure: biological dusts, mineral dusts, and gas and fumes $[23,24]$. Also, we assigned a summary exposure level to each survey participant for exposure to dust, gas or fumes (DGF) that was the highest level the individual had attained among the three types of exposure.

\section{Measurement of outcome frequency}

It was possible to determine whether a subject had fulfilled any one of the four criteria for a severe exacerbation of asthma in the past year. However, the survey instrument did not yield the frequency of each of the four different events that contributed to this variable, so we used 1-yr cumulative incidence (rather than incidence rate) to measure outcome frequency. The period of observation for both the occupations (with their associated exposures) and the outcome was the 12 months before the survey. To calculate the 1-yr cumulative incidence, the denominator was all participants at risk, the numerator was the number of participants from the denominator who had experienced at least one severe exacerbation event in the past year, and the resulting ratio was expressed as a percentage.

\section{Statistical analyses}

Regression models were used to estimate the association between severe exacerbation in the past year and occupational groups or exposures. A separate regression model was fit for each occupational category using subjects with only white collar jobs as the common comparison group and excluding from the model subjects who reported other occupations. Also, a separate regression model was fit to estimate the effect of each exposure assessed by the JEM. We constructed regression models using generalised estimating equations with a binomial response, log link and a cluster-level variable for country. Also, terms were included in each model for the potential confounders age (continuous), sex and cigarette smoking status (with former and current compared to never). We calculated and reported relative risk (RR) for any occupation or exposure category that had two or more participants with severe exacerbation. We tested for effect modification by sex to determine whether positive findings were limited to either males or females. Statistical analyses were accomplished using STATA SE 10.1 (Stata Corporation, College Station, TX, USA) and SAS Statistical software version 9.2 (SAS Institute Inc, Cary, NC, USA). Statistical significance was defined as $\mathrm{p} \leqslant 0.05$ and borderline statistical significance was $0.05<\mathrm{p} \leqslant 0.10$.

We estimated the population attributable risk percentage (PAR\%) for the occupational contribution to severe exacerbation of asthma with a standard equation that uses RR adjusted for potential confounders. The equation is:

$$
\mathrm{PAR} \%=((\operatorname{Pc}(\mathrm{RR}-1)) / \mathrm{RR}) \times 100
$$

in which Pc represents the proportion of severe exacerbation cases that had any high exposure to DGF [25]. We chose the RR for any high exposure to DGF to calculate the PAR\%, because this variable represents a broad range of occupational exposures, both sensitising and non-sensitising agents, that can exacerbate asthma.

\section{RESULTS}

\section{Characteristics of the $\mathbf{9 6 6}$ survey participants}

The 966 working adults with asthma included somewhat more females $(n=518,54 \%)$ than males, the mean \pm SD age was $42.0 \pm 7.1$ (range 28.6-56.0 yrs), and nearly half had never smoked cigarettes $(n=445,46 \%)$. A greater number were from the random sample $(n=504,52 \%)$ than the symptomatic sample, and the four countries with the largest numbers were Sweden $(n=275,28 \%)$, Spain $(n=149,15 \%)$, UK $(n=119,12 \%)$ and France $(n=111,11 \%)$. Self-reported work-related exacerbation of asthma symptoms was common: $22 \%(n=217)$ of the participants reported that jobs held in the past 12 months made their chest tight or wheezy.

\section{Severe exacerbation of asthma}

Among the 966 working adults with current asthma, 74 reported having at least one severe exacerbation event in the past 12 months, for a $1-y r$ cumulative incidence of $7.7 \%$. The most common of the four severe exacerbation events was seeking care for breathing problems in an emergency room, which was reported by 52 , or $70 \%$, of the severe exacerbation 
cases. Many fewer participants reported using oral steroids when needed (15 out of 74, 20\%), being hospitalised overnight due to a breathing problem $(n=12,16 \%)$, or being treated at home in an emergency for breathing problems $(n=6,8 \%) .11$ participants who reported emergency room care also reported one of the other exacerbation events: eight reported hospitalisation, two care at home, and one steroids when needed.

\section{Frequency of severe exacerbation by characteristics of participants}

Severe exacerbation of asthma was more common in females than males, and in the symptomatic sample than the random sample (table 2). By cigarette smoking status, the percentage severe exacerbation for former smokers $(4.1 \%)$ was significantly less than for current smokers $(10.6 \% ; \mathrm{p}=0.008)$, and the value for never smokers $(7.9 \%)$ was between the other two. By country, the outcome was most common in Italy $(16.7 \%)$ and Spain $(14.1 \%)$, and least common in Estonia $(0 \%)$ and France $(2.7 \%)$. Those with severe exacerbation were somewhat younger on average than other participants, with mean ages of $40.6 \pm 7.3 \mathrm{yrs}$ and $42.1 \pm 7.1$ yrs, respectively ( $p=0.085$ by unpaired $t$-test).

\section{Severe asthma exacerbation by occupation}

The 1-yr cumulative incidence and RR for severe asthma exacerbation by occupation were determined (table 3). Many

\begin{tabular}{|c|c|c|c|}
\hline Characteristics & Subjects & $\begin{array}{c}\text { Severe } \\
\text { exacerbation }\end{array}$ & p-value ${ }^{\#}$ \\
\hline \multicolumn{4}{|l|}{ Sex } \\
\hline Females & 518 & $47(9.1)$ & 0.076 \\
\hline Males & 448 & $27(6.0)$ & \\
\hline \multicolumn{4}{|l|}{ Smoking status } \\
\hline Never & 445 & $35(7.9)$ & 0.010 \\
\hline Former & 267 & $11(4.1)$ & \\
\hline Current & 245 & $26(10.6)$ & \\
\hline Unknown & 9 & $2(22.2)$ & \\
\hline \multicolumn{4}{|l|}{ Type of sample } \\
\hline Random & 504 & $32(6.3)$ & 0.109 \\
\hline Symptomatic & 462 & $42(9.1)$ & \\
\hline \multicolumn{4}{|l|}{ Country } \\
\hline Belgium & 31 & $2(6.5)$ & 0.024 \\
\hline Estonia & 10 & $0(0)$ & \\
\hline France & 111 & $3(2.7)$ & \\
\hline Germany & 32 & $2(6.3)$ & \\
\hline Iceland & 58 & $3(5.2)$ & \\
\hline Italy & 36 & $6(16.7)$ & \\
\hline Norway & 54 & $2(3.7)$ & \\
\hline Spain & 149 & $21(14.1)$ & \\
\hline Sweden & 275 & $24(8.7)$ & \\
\hline Switzerland & 60 & $2(3.3)$ & \\
\hline UK & 119 & $7(5.9)$ & \\
\hline USA & 31 & $2(6.5)$ & \\
\hline
\end{tabular}

Data are presented as $\mathrm{n}$ or $\mathrm{n}(\%)$, unless otherwise stated. ${ }^{\#}$ : $\mathrm{p}$-value from Chisquared test or Fisher's exact test. high-risk occupations were blue collar jobs, but also "food processing" and "healthcare" jobs had elevated RRs. Those with statistically significant RRs were "bakery" (RR 7.9, 95\% CI 5.1-12.2), all "blue collar" occupations (RR 1.4, 1.1-1.8), and the subgroups "drivers" (RR 2.3, 95\% CI 1.03-5.0) and "other blue collar" (RR 2.7, 95\% CI 1.4-5.1). The 20 "other blue collar" participants included eight (40\%) "sculptors, painters and related art," three (15\%) "protective services not elsewhere classified," two (10\%) "garbage collectors," two (10\%) "hand launderers and pressers," and five others. The four severe exacerbation cases in the "other blue collar" category included both of the "hand launderers and pressers," one "sculptors, painters and related artists," and one "protective services workers." Occupations with elevated RRs that were borderline statistically significant $(0.05<\mathrm{p} \leqslant 0.10)$ included all "healthcare" occupations (RR 1.5, 95\% CI 0.95-2.4) and the subgroup "nurses" (RR 1.7, 95\% CI 0.99-2.9), and all "food processing" occupations (RR 2.2, 95\% CI 0.97-5.0). None of the interactions of occupation with sex was statistically significant.

We did not calculate RRs for any occupation with fewer than two severe exacerbation cases.

Four occupational subgroups had one case each and were not included in table 3: "food and tobacco processing" $(n=16)$ in the "food processing" category, and the three "blue collar" subgroups of "wood workers" ( $\mathrm{n}=8)$, "textile, leather and fur workers" $(n=6)$, and "printing workers" $(n=7)$. Another 12 sub-categories of "blue collar" workers had no severe exacerbation cases and usually few participants (i.e. $<10$ per sub-category) (data not shown).

\section{Severe asthma exacerbation by occupational exposure}

The 1-yr cumulative incidence and RR of severe exacerbation by occupational exposure were calculated (table 4). Study participants could have multiple occupational exposures and be counted in more than one of the exposure categories presented in table 4 . Based on the JEM, about one in 10 study participants (102 out of 966, 10.6\%) had high exposure to DGF at work. The low exposure categories for DGF subgroups had modest increases in the cumulative incidence of severe exacerbation of asthma except for low biological dust, which had a somewhat higher incidence of $11.1 \%$ and RR 1.7 (95\% CI 1.1-2.6). Cumulative incidence was clearly elevated for high exposure to any DGF (15.7\%) and the subgroups biological dust $(18.5 \%)$ and gas and fumes $(16.4 \%)$, and elevated but less so for high exposure to mineral dust $(11.1 \%)$. These categories with elevated incidence also had statistically significant RR, with RR 3.1 (95\% CI 1.9-5.1) for any high DGF exposure, RR 3.6 (95\% CI 2.2-5.8) for high biological dust, RR 2.5 (95\% CI 1.25.5) for high gas and fumes, and RR 1.8 (95\% CI 1.02-3.2) for high mineral dust. The tests for trend were statistically significant or borderline significant for all exposures except mineral dust, and there were no statistically significant interactions by sex.

\section{Population attributable risk percentage}

The estimate of PAR\% was based on the findings for any high DGF exposure. The adjusted RR to two decimal places was 3.14 and the proportion of severe exacerbation cases with exposure $(\mathrm{Pc})$ was $0.216,16$ out of 74 . The PAR\% for severe 
TABLE $3 \quad 1-y r$ cumulative incidence and relative risk (RR) of severe exacerbation of asthma by occupation

\begin{tabular}{|c|c|c|c|}
\hline Occupation $^{\#}$ & Subjects & Severe exacerbation & $\mathrm{RR}^{*}(95 \% \mathrm{Cl})$ \\
\hline Reference $^{+}$ & 645 & $40(6.2)$ & 1.0 (Reference) \\
\hline Nurses ${ }^{\S}$ & 43 & $6(14.0)$ & $1.7(0.99-2.9)$ \\
\hline Other medical and pharmacy (not nurses) & 57 & $6(10.5)$ & $1.3(0.7-2.3)$ \\
\hline Agriculture and forestry & 16 & $1(6.3)$ & \\
\hline Blue collarf & 186 & $18(9.7)$ & $1.4(1.1-1.8)$ \\
\hline Cleaners and caretakers & 46 & $3(6.5)$ & $0.8(0.3-1.8)$ \\
\hline Other metal workers & 23 & $3(13.0)$ & $1.6(0.7-3.9)$ \\
\hline Construction and mining ${ }^{\# \#}$ & 19 & $3(15.8)$ & $2.4(0.7-7.9)$ \\
\hline Drivers $\%$ & 14 & $2(14.3)$ & $2.3(1.03-5.0)$ \\
\hline Other blue collar ${ }^{f++}$ & 20 & $4(20.0)$ & $2.7(1.4-5.1)$ \\
\hline
\end{tabular}

Data are presented as $\mathrm{n}$ or $\mathrm{n}(\%)$, unless otherwise stated. ${ }^{\#}$ : a separate regression model was fit for each occupation, with white collar jobs as the common comparison group, and participants from other occupations not included in model. " : RR from regression models with cluster-level variable for country, and covariates for sex, age, and smoking status. RR not calculated if fewer than two severe exacerbation cases in occupation category. ${ }^{+}$: legislators, managers, administrators, clerks and remainder professional (white collar jobs). ${ }^{\# \#}$ : model would not converge until the continuous age variable was replaced with indicator variables based on age tertiles. ${ }^{++}$: mode would not converge until the continuous age variable was replaced with indicator variables based on age tertiles, and former and current smoking categories were combined into a single ever-smoked category. "Other blue collar" included eight "sculptors, painters, and related art," three "protective services not elsewhere classified," two "garbage collectors," two "hand launderers and pressers," and five others. ${ }^{s}: 0.05<p \leqslant 0.10$. " ": $p \leqslant 0.05 .{ }^{f}: p \leqslant 0.01$.

exacerbation due to work among employed adults with current asthma was:

$$
\begin{aligned}
& \mathrm{PAR} \%=((\mathrm{Pc}(\mathrm{RR}-1)) / \mathrm{RR}) \times 100= \\
& ((0.216 \times 2.14) / 3.14) \times 100=14.7 \%
\end{aligned}
$$

\section{DISCUSSION}

The ECRHS is a population-based, multinational study that has been a valuable source of insight into respiratory diseases. We analysed ECRHS II data for working adults with current asthma and determined that $14.7 \%$, or approximately one in seven, of severe exacerbation of asthma cases were associated with occupation. From another perspective, 14.7\% of severe exacerbation cases could possibly be prevented by eliminating high DGF exposures in the workplace. The finding that former smokers had significantly fewer exacerbation events than current smokers suggests that cessation of a non-sensitising exposure can be beneficial. Candidate workplaces for interventions to prevent work-related severe exacerbations of asthma are suggested by the high-risk occupations identified in the current study: bakery workers, drivers, other blue collar workers (including hand launderers) and nurses (table 3).

Both non-sensitising and sensitising occupational exposures were implicated. Non-sensitising agents are often suspected as the cause of asthma exacerbations at work. Consistent with this suspicion, we identified an elevated RR for high exposure to mineral dusts and to gas and fumes, which are predominantly non-sensitising agents. At the same time, RR was elevated for low and high exposure to biological dust, which represents mainly sensitising agents. Finally, the summary variable for high exposure to any DGF, which incorporates both sensitising and non-sensitising exposures, was associated with severe exacerbation of asthma.
$22 \%$ of the working adults with asthma reported that a job held in the past 12 months made their chest tight or wheezy. This finding is similar to results from a study of employed adults with asthma in Finland, in which 20\% reported their symptoms were caused or worsened by work at least weekly in the past month [8]. A population-based study conducted in Canada [7] used the ECRHS protocol and reported higher figures than observed in the current study. Specifically, 34\% of asthma cases with adult onset reported wheezing at or after working in their current job, and 31\% reported dyspnoea under the same circumstances [7].

\section{Impact of occupation on asthma}

A prior investigation based on ECRHS II data determined that $10-25 \%$ of new-onset asthma could be attributed to occupational exposures, and the annual incidence of new-onset OA was $\sim 250-300$ cases per million [17]. The working population of 27 nations in Europe was $\sim 176,000,000$ in 2000 for the age range 25-64 yrs [26]. This means there would have been $\sim 44,000-52,800$ new OA cases per year. An estimated $4.5 \%$ of ECRHS participants, aged 20-44 yrs, had current asthma [27]. Using this prevalence estimate, 7,920,000 of the 176 million workers would have had current asthma in 2000. Before estimating the number of asthma cases with work-related severe exacerbation in 12 months, we excluded OA cases with onset in the same time period. We decreased the $7,920,000$ prevalent cases by the upper estimate of 53,000 new-onset OA cases, yielding $7,867,000$ at risk for exacerbation. Using estimates from the current study, $7.7 \%$ of the $7,867,000$, or $\sim 605,800$, would have had severe exacerbations in a $1-y r$ period, and $14.7 \%$ of this latter group, or 89,000 , would have had a severe exacerbation related to work. With the numbers for $\mathrm{OA}$ and work-related severe exacerbation of asthma 


\section{TABLE $4 \quad$ 1-yr cumulative incidence and relative risk (RR) of severe exacerbation of asthma by occupational exposure}

\begin{tabular}{|c|c|c|c|c|}
\hline Occupational exposure by JEM & Subjects exposed & Severe exacerbation & $\mathrm{RR}^{\#}(95 \% \mathrm{Cl})$ & $\mathrm{p}$-value for trenc \\
\hline DGF* & & & & $<0.001$ \\
\hline Low & 296 & $24(8.1)$ & $1.3(0.8-2.0)$ & \\
\hline $\mathrm{High}^{+}$ & 102 & $16(15.7)$ & $3.1(1.9-5.1)$ & \\
\hline \multicolumn{5}{|l|}{ Type of DGF } \\
\hline Low $^{\S}$ & 234 & $26(11.1)$ & $1.7(1.1-2.6)$ & \\
\hline $\mathrm{High}^{+}$ & 27 & $5(18.5)$ & $3.6(2.2-5.8)$ & \\
\hline Mineral dust & & & & 0.21 \\
\hline None & 781 & $58(7.4)$ & 1.0 (reference) & \\
\hline Low & 131 & $10(7.6)$ & $1.1(0.5-2.1)$ & \\
\hline $\mathrm{High}^{\S}$ & 54 & $6(11.1)$ & $1.8(1.02-3.2)$ & \\
\hline High $^{\S}$ & 61 & $10(16.4)$ & $2.5(1.2-5.5)$ & \\
\hline
\end{tabular}

Data are presented as $\mathrm{n}$ or $\mathrm{n}(\%)$, unless otherwise stated. JEM: job-exposure matrix; DGF: dust, gas and fumes. ${ }^{\#}$ : from regression models with cluster-level variable for country, and covariates for sex, age, and smoking status. Regression models fit separately to determine effect of each type of DGF exposure. ": based on highest exposure to biological dust, mineral dust and gas and fumes. ${ }^{s}: p \leqslant 0.05 ;^{+}: p \leqslant 0.01$.

combined, the annual number of asthma cases impacted by occupation in 27 European nations would have ranged from a low of 133,000 to a high of 141,800 . These estimates suggest that occupation is an important contributor to asthma morbidity and loss of productivity in Europe.

\section{Sample size}

The cohort of working adults with current asthma was relatively large. Still, there was not the statistical power to reach conclusions about all occupations and all the occupational exposures included in the JEM. A study with a greater number of employed adults with current asthma could yield more stable estimates of the independent impact of various occupational exposures. However, the problem of collinearity could persist even with greater numbers of participants. The 10 severe exacerbation cases with high gas and fume exposure illustrate the collinearity issue. They included one-fifth $(n=1)$ of the cases with high biological dust exposure and one-half $(n=3)$ of the cases with high mineral dust exposure.

\section{Work-exacerbated asthma cases}

Any employed person with asthma can experience workrelated exacerbation of their symptoms, but that person will not necessarily be classified as a WEA case. In particular, many researchers and clinicians consider that when someone with OA experiences exacerbation of asthma symptoms due to the same workplace agent that caused the asthma, it is a continuation of the original OA rather than a new WEA case. This distinction is particularly relevant for medico-legal issues such as worker compensation. In the current study, the higher RRs for bakery workers and those working with sensitising agents such as biological dust suggest that some severe exacerbation cases could have responded to the agents that had caused their OA.
However, the methods of the current study kept the focus on the contribution of occupation to exacerbation, and away from asthma onset or the continuation of OA cases. First, we excluded current asthma cases that had experienced onset in the 2 yrs prior to ECRHS II participation, in order to avoid confusing the onset experience with any subsequent exacerbation. Secondly, a general population JEM was used to assess broad exposure categories relevant to exacerbation of asthma. Researchers have used an asthma-specific JEM [28] successfully in studies of all work-related asthma cases in ECRHS I [16] and of asthma onset in ECRHS II [17]. However, the asthma-specific JEM was developed with an emphasis on newonset asthma rather than exacerbation of asthma. For example, it probably characterises sensitising exposures more completely than non-sensitising exposures, but the latter are suspected to play a larger role in exacerbation of asthma. Consequently, the asthma-specific JEM was not used in the current study of exacerbation.

The characterisation of occupational exposure in a populationbased study is a challenge. Using a JEM yields less biased estimates of exposure than self-reports [29]. Still, the assignment of exposure in the current investigation was not based on knowledge of the actual experience of each participant, so nondifferential misclassification almost certainly occurred. This would have biased findings to the null.

\section{Strengths of the current study}

The current study is unique with respect to where it was conducted and how it defined, determined and expressed the occupational contribution to exacerbation of asthma [3-8]. First, in an increasingly interconnected world, the ECRHS afforded an opportunity to calculate effect estimates that reached across national borders. Also, the pooled data from 
many countries provided more stable estimates than are usually possible in country-specific studies. Secondly, this study focused on severe exacerbation of asthma, using more stringent criteria for exacerbation than in prior studies, perhaps with the exception of a study that used serial peak expiratory flow rate measurements to identify work-related patterns [3]. Thirdly, a JEM was used to assign occupational exposures to participants. Many of the prior studies did not even consider exposure in the operational definition of WEA $[3,6,7]$. Fourthly, other studies determined work-related status for each case individually, whereas the current study used a risk-set approach to estimate the RR of occupational exposure and then compute the PAR\%. Finally, the PAR\% from this study represents the percentage of severe exacerbation cases attributable to occupation. Previous studies have expressed WEA frequency as a percentage of all adults with asthma or of all working adults with asthma [3-8]

\section{Summary}

Occupational exposure to DGF makes an important contribution to severe exacerbation of current asthma among working adults, accounting for $\sim 14.7 \%$ of such cases. A variety of occupations are associated with severe exacerbation, and the high-risk occupational exposures include sensitising as well as non-sensitising agents. Efforts to prevent work-related asthma have succeeded in different occupational settings, including healthcare workers exposed to natural rubber latex [30], animal handlers in laboratories [31] and detergent production workers exposed to enzymes [32]. These interventions depended on an adequate understanding of the agents and how they were used. Future work-related asthma prevention efforts will depend on having a similar understanding of agents and workplaces, and additional research will be needed to generate this knowledge when it is lacking.

\section{STATEMENT OF INTEREST}

None declared.

\section{ACKNOWLEDGEMENTS}

The authors want to thank the participants and field staff for their invaluable contribution to the success of the European Community Respiratory Health Survey.

Author affiliations are listed as follows. P.K. Henneberger: National Institute for Occupational Safety and Health, Centers for Disease control and Prevention, Morgantown, WV, USA. M.C. Mirabelli: Centre for Research in Environmental Epidemiology (CREAL), Municipal Institute of Medical Research (IMIM-Hospital del Mar) and CIBER Epidemiología y Salud Pública (CIBERESP), Barcelona, Spain. M. Kogevinas: Centre for Research in Environmental Epidemiology (CREAL), Municipal Institute of Medical Research (IMIM-Hospital del Mar) and CIBER Epidemiología y Salud Pública (CIBERESP), Barcelona, Spain, and Dept of Social Medicine, Medicine School, University of Crete, Heraklion, Greece. J.M. Antó: Centre for Research in Environmental Epidemiology (CREAL), Municipal Institute of Medical Research (IMIM-Hospital del Mar) and CIBER Epidemiología y Salud Pública (CIBERESP), Barcelona, Spain, and Dept of Experimental and Health Sciences, Universitat Pompeu Fabra, Barcelona, Spain. E. Plana: Centre for Research in Environmental Epidemiology (CREAL), Municipal Institute of Medical Research (IMIM-Hospital del Mar) and CIBER Epidemiología y Salud Pública (CIBERESP), Barcelona, Spain. A. Dahlman-Höglund: Dept of Occupational and Environmental Medicine, Sahlgrenska University
Hospital, Gothenburg, Sweden. D.L. Jarvis: Respiratory Epidemiology and Public Health Group, National Heart and Lung Institute, Imperial College, London, UK. H. Kromhout: Institute for Risk Assessment Sciences, Environmental Epidemiology Division, Utrecht University, Utrecht, The Netherlands. L. Lillienberg: Dept of Occupational and Environmental Medicine, Sahlgrenska University Hospital, Gothenburg, Sweden. D. Norbäck: Dept of Medical Sciences, Uppsala University, Uppsala, Sweden. M. Olivieri: Unit of Occupational Medicine, University of Verona, Verona, Italy. K. Radon: Institute for Occupational, Social and Environmental Medicine, Hospital of the Ludwig-Maximilian, University Munich, Munich, Germany. K. Torén: Dept of Occupational and Environmental Medicine, Sahlgrenska University Hospital, Gothenburg, Sweden, and Dept of Allergology, Sahlgrenska University Hospital, Gothenburg, Sweden. I. Urrutia: Respiratory Dept, Galdakao Hospital, Galdakao, Spain. S. Villani: Section of Medical Statistics and Epidemiology, Dept of Health Sciences, University of Pavia, Pavia, Italy. J.P. Zock: Centre for Research in Environmental Epidemiology (CREAL), Municipal Institute of Medical Research (IMIM-Hospital del Mar) and CIBER Epidemiología y Salud Pública (CIBERESP), Barcelona, Spain.

\section{REFERENCES}

1 Chinn S, Jarvis D, Burney $\mathrm{P}$, et al. Increase in diagnosed asthma but not in symptoms in the European Community Respiratory Health Survey. Thorax 2004; 59: 646-651.

2 Balmes J, Becklake M, Blanc P, et al. American Thoracic Society Statement: Occupational contribution to the burden of airway disease. Am J Respir Crit Care Med 2003; 167: 787-797.

3 Bolen AR, Henneberger PK, Liang X, et al. The validation of workrelated self-reported asthma exacerbation. Occup Environ Med 2007; 64: 343-348.

4 Caldeira RD, Bettiol H, Barbieri MA, et al. Prevalence and risk factors for work related asthma in young adults. Occup Environ Med 2006; 63: 694-699.

5 Henneberger PK, Derk SJ, Sama SR, et al. The frequency of workplace exacerbation among health maintenance organisation members with asthma. Occup Environ Med 2006; 63: 551-557.

6 Johnson A, Toelle BG, Yates D, et al. Occupational asthma in New South Wales (NSW): a population-based study. Occup Med (Lond) 2006; 56: 258-262.

7 Johnson AR, Dimich-Ward HD, Manfreda J, et al. Occupational asthma in adults in six Canadian communities. Am J Respir Crit Care Med 2000; 162: 2058-2062.

8 Saarinen K, Karjalainen A, Martikainen R, et al. Prevalence of work-aggravated symptoms in clinically established asthma. Eur Respir J 2003; 22: 305-309.

9 Berger Z, Rom WN, Reibman J, et al. Prevalence of workplace exacerbation of asthma symptoms in an urban working population of asthmatics. J Occup Environ Med 2006; 48: 833-839.

10 Goe SK, Henneberger PK, Reilly MJ, et al. A descriptive study of work aggravated asthma. Occup Environ Med 2004; 61: 512-517.

11 Tarlo SM, Liss G, Corey P, et al. A workers' compensation claim population for occupational asthma. Comparison of subgroups. Chest 1995; 107: 634-641.

12 Blanc PD, Ellbjar S, Janson C, et al. Asthma-related work disability in Sweden. The impact of workplace exposures. Am J Respir Crit Care Med 1999; 160: 2028-2033.

13 McClellan VE, Garrett JE. Asthma and the employment experience. N Z Med J 1990; 103: 399-401.

14 Jajosky RA, Harrison R, Reinisch F, et al. Surveillance of workrelated asthma in selected U.S. states using surveillance guidelines for state health departments-California, Massachusetts, Michigan, and New Jersey, 1993-1995. MMWR CDC Surveill Summ 1999; 48: 1-20. 
15 Tarlo SM, Leung K, Broder I, et al. Asthmatic subjects symptomatically worse at work: prevalence and characterization among a general asthma clinic population. Chest 2000; 118: 1309-1314.

16 Kogevinas M, Anto JM, Sunyer J, et al. Occupational asthma in Europe and other industrialised areas: a population-based study. Lancet 1999; 353: 1750-1754.

17 Kogevinas M, Zock JP, Jarvis D, et al. Exposure to substances in the workplace and new-onset asthma: an international prospective population-based study (ECRHS-II). Lancet 2007; 370: 336-341.

18 Jarvis D. The European Community Respiratory Health Survey II. Eur Respir J 2002; 20: 1071-1079.

19 Accordini S, Corsico A, Cerveri I, et al. The socio-economic burden of asthma is substantial in Europe. Allergy 2008; 63: 116-124.

20 Toren K, Brisman J, Jarvholm B. Asthma and asthma-like symptoms in adults assessed by questionnaires - a literature review. Chest 1993; 104: 600-608.

21 EAEMP. Note for guidance on the clinical investigation of medicinal products in the treatment of asthma. London, European Agency for the Evaluation of Medicinal Products, 2002.

22 ILO. International Standard Classification of Occupations: ISCO88. Geneva, International Labor Office, 1990.

23 Sunyer J, Zock JP, Kromhout $\mathrm{H}$, et al. Lung function decline, chronic bronchitis, and occupational exposures in young adults. Am J Respir Crit Care Med 2005; 172: 1139-1145.

24 Matheson MC, Benke G, Raven J, et al. Biological dust exposure in the workplace is a risk factor for chronic obstructive pulmonary disease. Thorax 2005; 60: 645-651.
25 Rockhill B, Newman B, Weinberg C. Use and misuse of population attributable fractions. Am J Public Health 1998; 88: 15-19.

26 Eurostat. Employment by sex, age groups and nationality. http:// epp.eurostat.ec.europa.eu. European Commission. Date last accessed March 18, 2009.

27 Janson C, Anto J, Burney P, et al. The European Community Respiratory Health Survey: what are the main results so far? Eur Respir J 2001; 18: 598-611.

28 Kennedy SM, Le Moual N, Choudat D, et al. Development of an asthma specific job exposure matrix and its application in the epidemiological study of genetics and environment in asthma (EGEA). Occup Environ Med 2000; 57: 635-641.

29 de Vocht F, Zock JP, Kromhout H, et al. Comparison of selfreported occupational exposure with a job exposure matrix in an international community-based study on asthma. Am J Indust Med 2005; 47: 434-442.

30 LaMontagne AD, Radi S, Elder DS, et al. Primary prevention of latex related sensitisation and occupational asthma: a systematic review. Occup Environ Med 2006; 63: 359-364.

31 Folletti I, Forcina A, Marabini A, et al. Have the prevalence and incidence of occupational asthma and rhinitis because of laboratory animals declined in the last 25 years? Allergy 2008; 63: 834-841.

32 Schweigert MK, Mackenzie DP, Sarlo K. Occupational asthma and allergy associated with the use of enzymes in the detergent industry - a review of the epidemiology, toxicology and methods of prevention. Clin Exp Allergy 2000; 30: 1511-1518. 